\title{
Development of Lifetime Evaluation Method Using Multilayer Coating Chip
}

\author{
By Shinatora $\mathrm{CHO}^{1)}$, Shigeru YoKota ${ }^{1)}$, Kentaro HARA ${ }^{1)}$, Daisuke TAKAHASHI ${ }^{1)}$ \\ Yoshihiro ARAKAWA ${ }^{1)}$, Kimiya KomURASAKI ${ }^{2)}$ and Akira KOBAYASHI ${ }^{3)}$ \\ ${ }^{1)}$ Department of Aeronautics and Astronautics, The University of Tokyo, Tokyo, Japan \\ ${ }^{2)}$ Department of Advanced Energy, The University of Tokyo, Tokyo, Japan \\ ${ }^{3)}$ Joining \& Welding Res. Inst. Osaka University, Osaka, Japan
}

(Received August 18th, 2009)

\begin{abstract}
In order to improve Hall thruster's lifetime performance, A new lifetime evaluation method, lifetime estimation using multilayered coated chips was developed for channel wall erosion rate distribution measurement. This method uses small chips coated with alternate channel wall material and marker. By detecting the marker emission as a signal of erosion progress, this method enables direct and rapid erosion rate distribution measurements. In this study, the capability of this new method for erosion rate distribution measurement was tested and validated. Multilayer coated chips of two kinds using different marker metals were embedded into the acceleration channel wall. The channel-wall erosion rate distribution was then measured. The measured erosion rates were, respectively, $0.90 \mathrm{~nm} / \mathrm{s}$ and $0.75 \mathrm{~nm} / \mathrm{s}$ at $2 \mathrm{~mm}$ and $4 \mathrm{~mm}$ upstream from the channel exit.
\end{abstract}

Key Words: Hall Thruster, Lifetime Evaluation, Multilayer Coating, Sputtering

\section{Nomenclature}

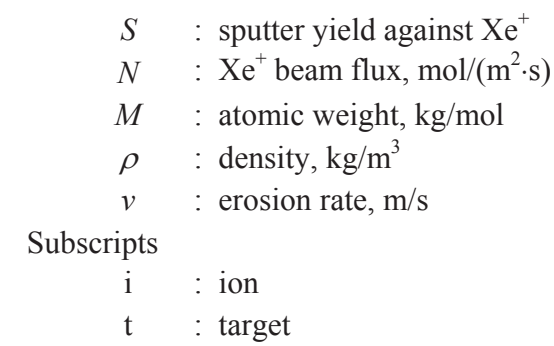

\section{Introduction}

A Hall thruster is a promising electric propulsion system because of its high specific impulse and thrust efficiency ${ }^{1}$. Like other electric propulsion systems, an important Hall thruster performance criterion is its lifetime because typical missions require continuous operation for up to $10,000 \mathrm{hr}^{2}$.

The Hall thruster lifetime is determined by erosion of the acceleration channel wall by ion sputtering. To improve the Hall thruster lifetime performance, development of lifetime estimation methods is necessary. Among the various proposed erosion rate measurement methods ${ }^{3), 4)}$, lifetime estimation using multilayer coated chips is a useful one because of its short measurement time and capability of erosion-rate distribution measurement. In our previous study, we conducted erosion rate measurement at the channel exit ${ }^{5)}$. In this study, this new method was developed further for spatial distribution measurement.

The Hall thruster's channel-wall erosion rate depends strongly on the axial position ${ }^{6}$. To evaluate the lifetime performance of a Hall thruster precisely, and to validate the results of numerical simulation, it is necessary to measure the spatial distribution of the channel wall erosion rate. For this purpose, lifetime estimation using multilayer coated chips is useful because of its high spatial resolution. Therefore, the objective of this study is to conduct erosion rate distribution measurements using this new method.

Multilayer coated chips of two kinds with different marker metals were embedded into the Hall thruster channel wall. Then the emission signals of both marker metals were observed simultaneously. Results show that the erosion rate distribution was measured successfully.

\section{Experiment}

\subsection{Principle of the measurement method}

Figure 1 presents a schematic of the lifetime estimation method using multilayer coated chips. A multilayer coated chip is embedded into the Hall thruster channel-wall. The multilayer film on the chip comprises alternate thin metal layers and thick ceramic layers. The thin metal layers are used as markers to detect the erosion rate of ceramic layers, whereas the thick ceramic layers represent the ceramic channel wall. When the Hall thruster operates, ion sputtering erodes the embedded chip and the surrounding channel wall. The emission of marker metal sputtered out from the thin metal layers is observed using emission spectroscopy. The spectrometer will detect the eroded marker metal as emission peaks. The channel wall erosion rate is therefore calculable from the intervals of periodic peaks of emission signals.

Erosion rate measurements can be done much more quickly using this method, in less than half an hour. Furthermore, the emission intensity fluctuation has no influence on accuracy, which is an important advantage over other real time erosion rate measurement methods. Moreover, this method has high spatial resolution because of the small multilayer coated chips. 


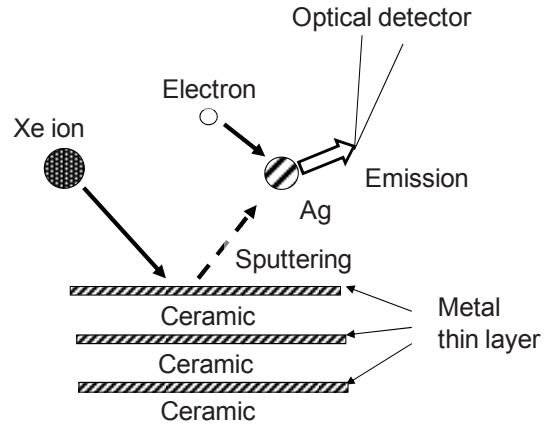

Fig. 1. Schematic of the lifetime estimation method using multilayer coated chips. The erosion rate is calculated from intervals of periodic emissions of metal layers.

\subsection{Erosion rate distribution measurement}

Figure 2 presents a diagram of the erosion rate distribution measurement. Multilayer coated chips containing different marker metals are embedded into the acceleration channel wall. When the Hall thruster operates and the chips and channel wall are eroded, each chip emits a distinct characteristic emission of its marker metal. Observing the emission history of all marker metals simultaneously enables real-time erosion rate distribution measurements. As the first step of measurements, chips of two kinds were used for this study.

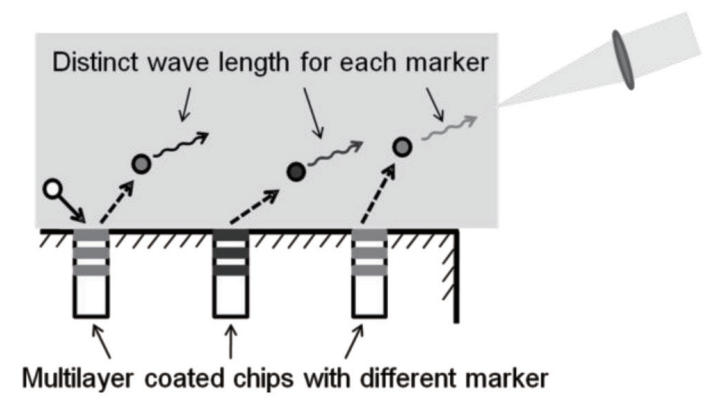

Fig. 2. Schematic of erosion rate distribution measurement. Each marker measures the channel wall erosion rate at the point where it is embedded. Two chips of different materials were used for this study.

\subsection{Multilayer coated chip}

The marker metal material was chosen as follows.

The erosion rate of a target material against the ion beam can be shown as presented below.

$$
v=N_{i} S \frac{M_{t}}{\rho_{t}}
$$

All parameters on the right-hand side except $N_{i}$ depend on the material of the target. We define $\kappa_{t}$ as follows.

$$
\kappa_{t} \equiv S \frac{M_{t}}{\rho_{t}}
$$

Material with high values of $S$ and $\kappa_{t}$ is appropriate for use as a marker. High $S$ means a high number density of marker material in the channel when the marker layer is eroded, which makes emission easier to detect. High $\kappa_{t}$ denotes a high marker-layer erosion rate, which shortens the time needed to erode marker layers. It therefore enhances the accuracy of measurement as a result.

Table 1 shows sputter yields and $\kappa_{t}$ against the $\mathrm{Xe}^{+}$beam of several marker candidates. Taking the availability of the material into consideration, $\mathrm{Cu}$ and $\mathrm{Ag}$ were used as marker metals in this study. Although $\mathrm{Cu}$ is also used as an anode material of the Hall thruster, the erosion rate measurement will show no interference by the emission of $\mathrm{Cu}$ from anode because the absolute value of the emission peak intensity is not necessary in this method. Only detection of the emission peaks is necessary.

Figure 3 shows multilayer coated chips used for this study. The chip base material is SUS304. Their diameter is $1 \mathrm{~mm}$. Three marker layers and two BN layers were coated alternately. The respective $\mathrm{BN}, \mathrm{Cu}$, and $\mathrm{Ag}$ layer thicknesses were $170 \mathrm{~nm}$, $43 \mathrm{~nm}$, and $17 \mathrm{~nm}$. The $\mathrm{Cu}$ layer was coated much more thickly than the Ag layer because we placed priority on detecting the emission peaks of $\mathrm{Cu}$. Chips were insulated from the thruster to avoid interfering with the Hall thruster operation.

The multilayer coated chips were manufactured using an ion beam sputtering coating device. The coating process was conducted at the Smart Processing Research Center, Osaka University. Table 2 shows the operation conditions of the coating device. To produce a coating layer precisely, the coating rate of each material was measured in advance. The results were $0.96 \mathrm{~nm} / \mathrm{min}, 8.8 \mathrm{~nm} / \mathrm{min}$, and $43 \mathrm{~nm} / \mathrm{min}$, respectively, for $\mathrm{BN}, \mathrm{Ag}$, and $\mathrm{Cu}$.

\begin{tabular}{|c|c|c|c|c|c|}
\hline Material & \multicolumn{4}{|c|}{ Sputter yield } & $\kappa_{t,}$ \\
\hline Ion energy, eV & 100 & 200 & 300 & 600 & 200 \\
\hline $\mathrm{Cu}$ & 0.26 & 0.79 & 1.29 & 2.44 & 5.64 \\
\hline $\mathrm{Ag}$ & 0.40 & 1.05 & 1.80 & 4.20 & 10.8 \\
\hline $\mathrm{Pt}$ & 0.19 & 0.72 & 1.25 & 2.23 & 6.55 \\
\hline $\mathrm{Au}$ & 0.16 & 1.00 & 1.83 & 3.10 & 10.2 \\
\hline $\mathrm{Al}$ & 0.06 & 0.24 & 0.45 & 1.02 & 2.40 \\
\hline $\mathrm{Fe}$ & 0.06 & 0.29 & 0.54 & 1.2 & 2.06 \\
\hline $\mathrm{Ti}$ & - & 0.13 & 0.24 & 0.5 & 1.38 \\
\hline
\end{tabular}

Table 1. Characteristics of marker candidates.

Table 2. Operation conditions of coating device.

\begin{tabular}{|l|l|}
\hline \multicolumn{1}{|c|}{ Parameter } & \multicolumn{1}{c|}{ Value } \\
\hline Working gas & Argon \\
\hline Mass flow rate & $0.20 \mathrm{mg} / \mathrm{s}$ \\
\hline Acceleration voltage & $1000 \mathrm{~V}$ \\
\hline Deceleration voltage & $-500 \mathrm{~V}$ \\
\hline Ambient pressure & $7.9 \times 10^{-3} \mathrm{~Pa}$ \\
\hline
\end{tabular}

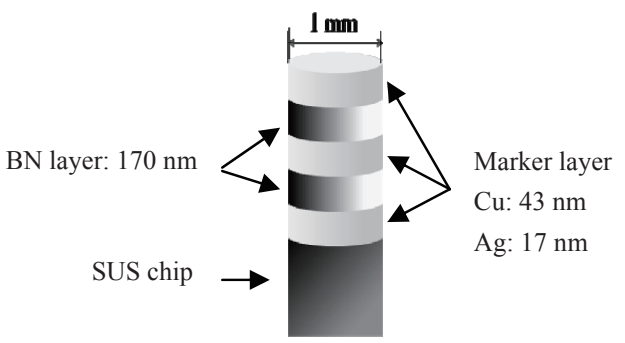

Fig. 3. Schematic of multilayer coated chip. Chips were insulated from the thruster to avoid affecting the thruster operation. 
Table 3. Operation conditions of Hall thruster.

\begin{tabular}{|l|l|}
\hline \multicolumn{1}{|c|}{ Parameter } & \multicolumn{1}{c|}{ Value } \\
\hline Propellant & Xenon \\
\hline Mass flow rate & $1.08 \mathrm{mg} / \mathrm{s}$ \\
\hline Discharge voltage & $150 \mathrm{~V}$ \\
\hline Discharge current & $2.0 \mathrm{~A}$ \\
\hline Magnetic flux density & $18 \mathrm{mT}$ \\
\hline Ambient pressure & $2.5 \times 10^{-2} \mathrm{~Pa}$ \\
\hline
\end{tabular}

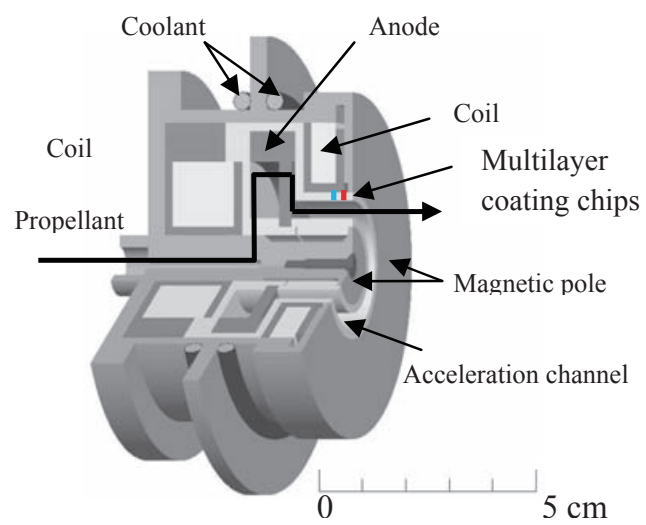

Fig. 4. Cross section of the $500 \mathrm{~W}$ class UT Hall thruster.

\subsection{Hall thruster}

Figure 4 shows the $500 \mathrm{~W}$ class magnetic layer type Hall thruster developed at The University of Tokyo. The inner and outer diameters of the acceleration channel are, respectively, 22 $\mathrm{mm}$ and $30 \mathrm{~mm}$. The channel length is 14- $\mathrm{mm}$ long and the wall material is boron nitride $(\mathrm{BN})$. The operation conditions are presented in Table 3.

Multilayer coated chips were lined up in the axial direction. The $\mathrm{Ag}$ and $\mathrm{Cu}$ chips were set respectively $2 \mathrm{~mm}$ and $4 \mathrm{~mm}$ upstream of the thruster exit on the outer acceleration channel-wall. The presence of multilayer coated chips did not affect the Hall thruster operation. The operation parameters of the Hall thruster were identical, irrespective of whether the chips were embedded or not.

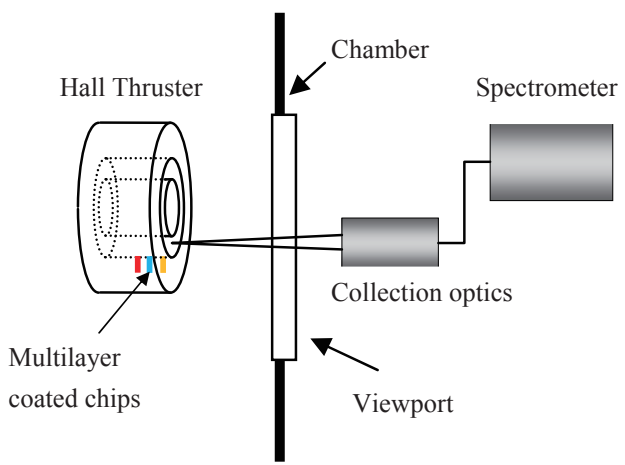

Fig. 5. Schematic of the measurement system. Collection optics were focused on the channel exit where the chips were lined up.
Table 4. Measurement setting of optical system.

\begin{tabular}{|l|l|}
\hline \multicolumn{1}{|c|}{ Parameter } & \multicolumn{1}{c|}{ Value } \\
\hline Sampling rate & $1 \mathrm{~Hz}$ \\
\hline Exposure time & $1 \mathrm{~s}$ \\
\hline Wavelength range observed & $310-350 \mathrm{~nm}$ \\
\hline Wavelength resolution & $0.04 \mathrm{~nm}$ \\
\hline
\end{tabular}

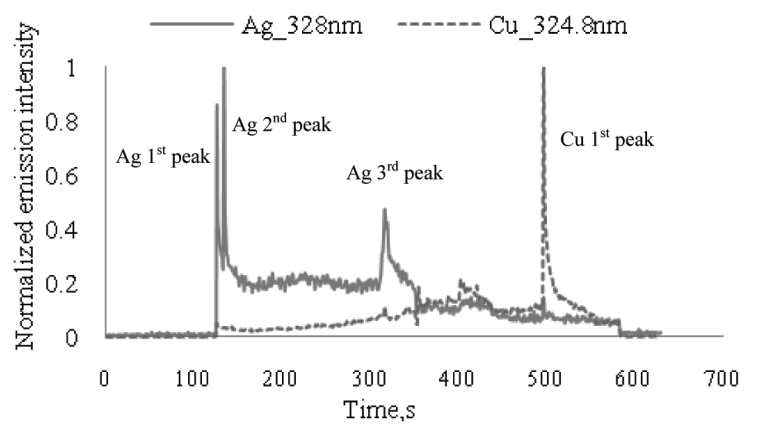

Fig. 6. Emission history of Ag I (328 nm) and $\mathrm{Cu} \mathrm{I} \mathrm{(324.8} \mathrm{nm).} \mathrm{The}$ emission intensity is normalized for simplification. Three peaks for Ag and one peak for $\mathrm{Cu}$ were observed.

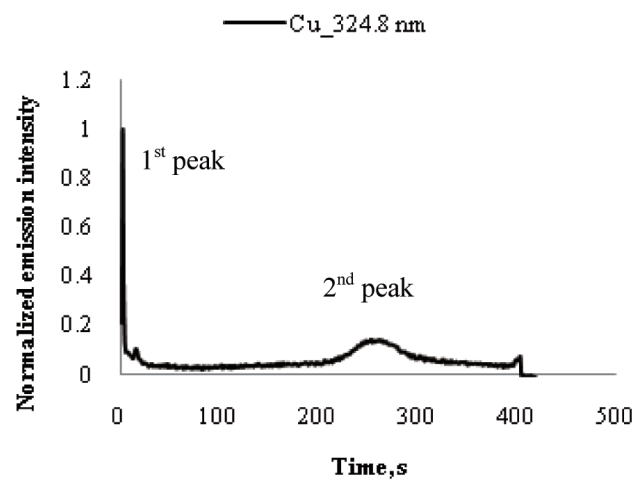

Fig. 7. Emission history of $\mathrm{Cu} \mathrm{I}(324.8 \mathrm{~nm})$. Two emission peaks of $\mathrm{Cu}$ were observed.

\subsection{Optical system}

Figure 5 shows the optical system. The collection optics was focused on the channel exit plane, where the chips were lined up. The emission history of Ag I (328 nm) and Cu I (324.8 nm) were measured simultaneously using the same spectrometer. Table 4 shows the spectrometer measurement setting. The dead time of the spectrometer was negligible.

\section{Results and Discussion}

Figure 6 shows the emission history of marker metals $\mathrm{Ag}$ $(328 \mathrm{~nm})$ and $\mathrm{Cu}(324.8 \mathrm{~nm})$. Peaks of emission signal of both marker metals were observed. Three peaks of emission signals for $\mathrm{Ag}$ and one for $\mathrm{Cu}$ were detected.

The first peak and second peak of Ag are very close, which presumably results from the unstable ignition of the Hall thruster, which caused a very high erosion rate ${ }^{7}$. The Hall thruster operation was stable after the second peak of Ag was observed. The interval of second and third emission peak of Ag was $190 \mathrm{~s}$; the BN erosion rate calculated from the interval was $0.90 \mathrm{~nm} / \mathrm{s}$, which is a reasonable value compared with that of SPT- $100^{6)}$. 
The first peak of $\mathrm{Cu}$ is delayed because the chip was embedded too deeply into the channel wall. Because of the malfunction of the Hall thruster, the observation was stopped before the second and third peaks of $\mathrm{Cu}$ emission were to be observed. Second and third emission peaks would have been observed with longer operation.

The emission history of $\mathrm{Cu}$ was observed separately afterward under identical experimental conditions. The result is shown in Fig. 7. Two emission peaks of $\mathrm{Cu}$ atoms were observed. The second emission peak was dull. Therefore, the peak center was determined using Gauss fitting. The erosion rate calculated from the interval of two peaks was $0.75 \mathrm{~nm} / \mathrm{s}$. The third marker layer's emission peak could not be observed. Presumably, the third peak was too collapsed to be detectable.

The emission peaks of $\mathrm{Ag}$ and $\mathrm{Cu}$ were observed simultaneously; the erosion rates at two different places at the channel wall were measured. The calculated erosion rate was faster at the place nearer the channel exit. This tendency is reasonable compared with measurements conducted through a long time of operation ${ }^{6}$.

\section{Conclusion}

This study confirmed that the multilayer coating method can provide an erosion rate distribution measurement.

Multilayer coated chips of two kinds using $\mathrm{Cu}$ and $\mathrm{Ag}$ as marker metals were embedded into a Hall thruster acceleration channel. The emission histories of both marker metals were observed simultaneously. The peak emission signals of the respective marker metals were observed. The erosion rates calculated from intervals of emission peaks were, respectively, $0.90 \mathrm{~nm} / \mathrm{s}$ and $0.75 \mathrm{~nm} / \mathrm{s}$ at $2 \mathrm{~mm}$ and $4 \mathrm{~mm}$ upstream from the channel exit. The measured erosion rate distribution was reasonable.

\section{References}

1) Arakawa, Y., Komurasaki, K.and Hirakawa, M.: A Hall Thruster, $J$. of the Japan Soc. for Aero. And Space Sci, 40 (1998), pp.146-152.

2) Yim, J. T., Keidar, M. and Boyd, I. D.: An Evaluation of Sources of Erosion in Hall Thrusters, AIAA Paper, 2005-3530, July 2005.

3) Jacobson, D. T.: Investigation of the Erosion Characteristics of a Laboratory Hall Thruster, AIAA Paper, 02-4257 (2002).

4) Garner, C. E. , Brophy, J. R., Polk, J. E. and Pless, L. C.: A 5,730-Hr Cyclic Endurance Test of the SPT-100, AIAA Paper, 95-2667 (1995).

5) Yokota, S., Komurasaki, K. and Arakawa, Y.: Development of Hall Thruster Life Time Measurement Method Using Multilayer Coated Chip, Institute of Applied Plasma Science, 17 (2008).

6) Eagle, W. E. and Boyd, I. D.: The Erosion Prediction Impact on Current Hall Thruster Model Development, AIAA Paper, 2008-5087.

7) Yamamoto, N., Yokota, S., Komurasaki, K. and Arakawa, Y.: Measurement of Erosion Rate by Absorption Spectroscopy in a Hall Thruster, Rev. Sci. Instrum., 76 (2005), 083111. 